\title{
A Study of Flexible Management in Enterprise Human Resources Management
}

\author{
Mingqiang Zhu \\ School of Civil Engineering and Architecture, Wuhan Polytechnic University \\ Wuhan 430023, China \\ Xfzmq7912@163.com
}

\section{Keywords: Human resources; Flexible management; Rigid management; Core competencies}

\begin{abstract}
Follows the economic globalization and the knowledge economy arrival, the traditional rigid management pattern is restricting the enterprise human resources innovation and the initiative seriously, the enterprise human resources only then implements the flexible management to be able to adapt the now environment of competition. Introduced the human resources flexibility management definition, the domestic and foreign scholars in this domain research condition and the enlightenment. The domestic and foreign flexibility management study achievement is rich, has certain breadth and the depth, but also has the insufficiency. The futurology not only need conduct the qualitative investigation, must carry on the quantitative analysis; Not only need develop and the rich theoretical knowledge, must apply in the human resources flexibility management case which these theories the reality occurs, carries on the detailed description, the explanation to it, discovers may use for the regular thing which instructs the enterprise to practice, establishes the science the system info, thus is further rich and in the development enterprise's human resources flexibility management theory.
\end{abstract}

\section{Introduction}

Enters into the era of knowledge economy in the humanity from the industrial age today, enterprise's competitive advantage originates from the knowledge innovation and organization's unceasing study, thus the knowledge worker was already mentioned as the knowledge carrier is higher than other resources in the position, the knowledge staff became the enterprise to have the competitive advantage in the global character intense market competition the strength fountainhead, the business management center of gravity also changed "the human" along with it from "the thing". Human's emotion, person's disposition becomes the question which the superintendent must take seriously, how to cause the staff own knowledge, the thought that to be able to offer voluntarily to the enterprise is an important content which each enterprise superintendents and the human resources development department must try to ponder.

\section{Flexible Management Connotation}

"The flexibility" is makes a general reference the life body to adapt the change ability and the characteristic, like periphery the basis environment, the opportunity change nimble reflection, the rapid motion, avoid the threat and the adjustment strategy. Therefore, "the flexibility" includes the versatile meaning, namely has the adaptation different situation ability. Not only has that it also included strongly, toughness, to endure the negative influence ability which the change brings. As a management idea, the flexible management is opposite in the rigid management raises. The rigid management refers to "take the rules and regulations as the center", relies on methods and so on system restraint, discipline surveillance and rewards and punishment rule carries on the management to the enterprise staffs, this was the 20th century general management pattern. But the flexible management is refers to "take the human as the center", based on enterprise's common values and the culture, the energetic atmosphere carries on the personification management, it is in studies person's psychology and in the behavior rule foundation, selects the non-compulsory method, has one kind of latent persuasive power in the staff mind, thus becomes the organization will individual aware motion one mode of administration. 
Since the 21st century, the capital, technical, the intelligence global flowing and the proliferation, the enterprise tends to gradually in "does not have". Human resources' flexible management pattern has broken through the rigid management pattern visible boundary, it did not rely on the fixed organizational structure, the stable rules and regulations carries on the management, but so on detachment condition's change changed along with the time external environment, was one kind of reflection agile, the flexible brand-new human resources management pattern. Therefore, the human resources flexibility management is also must manifest the interpersonal relationship in human resources management process the harmony, between team's cooperation, organizational structures nimble, to exterior response's agile, as well as toughness which and so on flexible realizes to the goal the characteristics.

The traditional management is operates take "the tube person" as the core, the so-called system, the discipline are the attempt through serve tube's purpose to person's activity limit. Under this kind of management concept, the human is the thing dependency. Its malpractice is, will fulfill exactly some rules and regulations to reduce the organized activities inevitably the flexibility, will affect the organization and external environment coordinated. Puts in the negative passive condition the staff, lacks participates in the management, participation decision-making consciousness on own initiative, has limited its enthusiasm and the creativity. Organization's ossification and work quantification's at the same time has also created staff's inertia, causes the staff only to strive for to complete the duty-bound work constantly. But the flexibility management "the self-improvement", take satisfies staff's top level to need as a goal, can the deep level stimulate staff's job motivation, strengthens staff's host sense of responsibility, not only makes its own initiative to raise the respective working standard, moreover is willing to unearth its potential, displays its talent, makes the superior work achievement.

\section{Flexible Management and Rigid Management}

The flexible management is opposite in the rigid management raises. The rigid management refers to "as the center relies on methods and so on system restraint, discipline surveillance, rewards and punishment rule take the rules and regulations" to carry on the management to the enterprise staffs. This is the 21 st century general management pattern. The flexible management is refers to "take the human as the center" the personification management which based on enterprise's common values and the culture, the energetic atmosphere carries on, it is in studies person's psychology and in the behavior rule foundation, selects the non-compulsory method, has one kind of latent persuasive power in the staff mind, thus becomes the organization will individual aware motion.

The rigid management is refers to "take the rules and regulations as the center", relies on methods and so on system restraint, discipline surveillance, rewards and punishment rule the management which carries on to the enterprise staffs. This is the 21 st century general management pattern, like famous Taylor management pattern: The Taylor management theory regards as the human "the economic man", "machine's appendix", it stressed that organizes the authority and the specialized labor division. Taylor thought that because between organization interior various essential factors relates is complex, usually is the multi-dimensions, multi-level, therefore in the management practice, the organization should pay great attention by the strict control system primarily. But this rigidity mode of administration, although promoted the management standardization, but cannot arouse the staff lasting exuberant work enthusiasm, on the contrary this kind rational, the rigid mode of administration usually displayed non-rational, in the rich emotion demand and the entire management system management system's multi-dimensional contacting exactly with the staff constituted the contradiction. But the flexible management does not repel in the management the rigid ingredient, it is only phenomenon and so on heavy item light person who, method strong, deficient elasticity displays to the traditional tube pattern in one kind of dialectical denial, is one kind develops the good and discard the bad. The angle which practices from the enterprise, the rigid management and the flexible management are inseparable. The rigid management is the supervisory work premise and the foundation, it has constructed a bare bone for the entire supervisory work, had stipulated the management goal, the scope, the time, the space and the essential rigid method, cause the enterprise and individual all behaviors under this frame the order movement. Does not have the rules and regulations enterprise is inevitably the disorder, chaotic, its flexible management also inevitably loses the 
standpoint, therefore said that the rigid management is the flexible management foundation; But the rigid management must depend upon the flexible management to promote, the organization lacks the flexible management, the staff lacks the work the enthusiasm and the fervor, the rigid management also with difficulty penetrates. In modern market economy movement, any successful enterprise, no matter its scale size, also, no matter its capital to be whether abundant, succeeds behind some common knack in it - - is surely management hard and soft developing simultaneously, the tamper force with mercy; That is in the actual supervisory work, insisted that the rigid management and the flexibility manage the principle which two wheels transfer together, and consummates the tamper force with mercy unceasingly in organization's development the integrated management method, can cause the management practice work to carry on smoothly. In short, the organization leaves the rigid management, its management is the water without a source, does not have this wood; But the enterprise leaves the flexible management, its management is a stagnant water deep pool inevitably, is unable the sustained development. Therefore said that the flexible management is to the rigid management sublimation.

\section{Flexible Management Characteristic}

Flexible Management Intrinsic Actuation. Because the flexible management's most major characteristic mainly lies in depends upon the authority influence, but is relies on staff's mechanism, depends upon the human nature to liberate, the authority equally, the democratic management, stimulates each staff's intrinsic potential, the initiative and the creative spirit from the heart of hearts, enables each staff to achieve truly has ease of mind, spares no effort for enterprise's development, but develops the new fine achievement unceasingly, guaranteed that the enterprise has the superiority in the intense market competition, therefore, the flexible management has the obvious intrinsic actuation. However, in reality work, only then, when the enterprise standard transforms truly for staff's aware consciousness, the business goal transforms truly as staff's spontaneous motion, the flexible management's intrinsic driving influence can form, and the self-binding force will only then produce.

Flexible Management Influence Durability. This characteristic main performance for in the flexible management, must transform the enterprise external each kind of administrative provisions into the staff innermost feelings voluntary pledge, and this kind of innermost feelings pledged finally transforms for staff's aware motion. Because this conversion process needs the enterprise to make the long-term relentless effort, therefore it requires the time. But in the reality, as a result of the staff individual difference, enterprise culture's tradition as well as environment's restriction and so on various factor's influence, between the enterprise overall goal and staff individual goal often has each kind of difference and is with difficulty coordinated. However once this kind of coordinated work achieves consistently through the flexible management, will then obtain the relative independence in staff's understanding, it will have formidable and the lasting influence to the staff.

Flexible Management Drive Validity. The flexible management's drive validity mainly displayed in it manifests the human multi-level to need the aspect, the Masiluo (1943) 5 levels needs the theory to be possible to divide into the physiological drive, the security requirements, the public relations demand, the respect demand and the self-realization demand from the preliminary to high-level. The Herzberg (1959) double factor theory pointed out: To the human, the underlying bed demand which must satisfy for the maintenance life, like the physiological drive, the security requirements, the social interaction demand is equal to the hygienic factor; But is respected and realizes the self-high-level demand to belong the drive factor. But the flexible management is mainly through meets staff's high-level need, stimulates the staff to the work highly warmly, thus the flexible management has the effective drive function.

Flexible Management Rapid Compatibility. It mainly displays in adaptation environmental variation timeliness and the dealing with ability aspect. In present era, because the worker culture quality enhances day by day, periphery they can act according to the environment change to give full play to the ability and wisdom, the nimble response, the rapid motion, to avoid the threat; Simultaneously in the flexible management also includes the versatile meaning, namely it not only has the prompt discovery environmental variation ability, but also has strong and the tough characteristic, can deal with each kind of influence which positively the environmental variation brings; Moreover the flexible management's 
rapid reactivity also manifests for in the situation which the market element of certainty forecast with difficulty day by day in the intense market competition, the enterprise can reorganize its manpower and the technological resource accurately promptly, obtains the competitive advantage and enhances the profit. In brief, human resources' flexible management's characteristic may the system summary be: Intrinsic again in external, the psychology in physics, teaches by example again in teaches by word again, definitely again in the denial, drove that in the control, practical in discusses principles again. But in human resources management flexibility characteristic, then mainly displays for must manifest "harmonious, harmonious, the cooperation in human resources management process, nimble, agile and toughness" and so on aspects.

\section{Human Resources Flexibility Management Method}

Flexibility Needs the High Quality Staff. Adapts flexible production technology which the customer personalization needs, is one intelligence production operation way. Therefore, it requests all staff to understand that the modern production technology, masters many kinds of skill skills skilled, has the independent processing question ability under Information networking's condition. The keen response's enterprise staff troop by has the knowledge, to have the information, the adaptation environment, and the personnel who awards the authority is been composed. A flexible management's organization first should be the study organization. Through studies unceasingly, gains the new knowledge which and the new skill promptly the project needs. At the same time, through overlapping training, these people have the vast skill, can use the open information environment effectively, thus become the flexible management enterprise's core resources. The incentive mechanism is also an establishment keen staff troop's important component. It including thorough consideration economical drive and non-economical drive. The non-economy drove that mainly includes the equality of treatment staff, to respect the staff, to entrust with it to utilize own wisdom work the authority, lets it obtain realizes own value feeling of satisfaction. For instance, in the Shanghai General Electric Company, implements the flexible management an important content is the full authorization. Advocated ", since let you do, the authorization will give you, me excessively much will not involve". Thus, changed the traditional imperative mood mode of administration, the management turned the autonomy to a great extent by the heteronomy, namely independent management.

Establishment Highly Effective Teams.The administrative personnel discovered that in the changeable environment, the team is more nimble than the traditional department structure or the other form's stable community, responds is more rapid, it may combine fast, reorganize and dismisses. The team can promote the employee to participate in the decision-making process, it is helpful in the administrative personnel's strengthens organization's democratic atmosphere, enhances staff's enthusiasm. This kind take the flexible management as the characteristic hypothesized team, is called in IBM "the market opportunity management flow". IBM the resources concentrates the company limited most can create effectively the customer value in the market opportunity. First, the company to will enter system's market opportunity to carry on the selection through the market regulation flow, once an opportunity is selected, will accept into it the flow, the corresponding personnel will then start to enter into the flow spirit . These roles include: The opportunity discovered that the human, the opportunity judges the person, opportunity consultant, the opportunity person in charge, opportunity business manager, the itemized written proposal design group people in charge, itemized written proposal and the solution frame design team, the quality control person, the project implementation team, the project group people in charge, the customer feeds back the assembler and the resources negotiator.

Realize the Flexibility Management, the Values is the Cores. The flexibility organization, is must have the contingency nature, the compatible staff to compose highly, what but commands the function between the two is the flexibility enterprise culture. Enterprise culture's flexibility is stronger, the contingency nature, the compatibility are stronger, is more advantageous to flexible management realization. The values are the enterprise culture core. One is enterprise's values, it is about enterprise value certain faith, the tendency, the position and the manner viewpoint, is playing the behavior guidance, the evaluation criteria, the appraisal principle role, is instructs the enterprise behavior a series of basic 
maxims and the creed. When some kind solves the question value idea and the way may continue and solve the organization question effectively, this kind will solve the question truth to become enterprise's mutual recognition, subsequently will become the natural truth, this kind of truth will be values. HP Corporation's values are, the enterprise development fund self-provides primarily, the advocate reform and innovates, emphasis collective team spirit. In this core values foundation, the company formed gradually had oneself bright characteristic enterprise culture. This kind is called "HP pattern" the enterprise culture, is one kind even more pays great attention the customer, the shareholder, the company staff's benefit request, takes the leader to be able and other each kind of HP stimulates the creation factor the cultural system. In this cultural system, HP pattern pays great attention by, the fair manner to serve sincerely the consumer; in the enterprise interior advocated that all people being equal and everybody respect. In the practical work, advocated that the self-control, the self-control and the result management, advocate the temperate transformation, dismisses the staff not easily, is also not blind expands the scale, insisted that loose, free work environment, cultivates publicly, transparent, the democracy work style diligently. HP's enterprise culture and the modes of business operation which uses above this stimulates company's development enormously, promoted the company operating results to grow powerfully.

Establishment Flexible Enterprise Culture. The enterprise culture is take organizes the values which in the history forms as a core, take manages the system standard the behavior and the life style as the representation energetic culture and the material civilization synthesis, has the influence and the standard enterprise interior staff thought and the behavior function. The enterprise culture is also a flexible human resources management important aspect, the human is enterprise's capital stock, enterprise's all activities is "humanist". To human resources' use, the enterprise strives to excel the modulation percentage construction at the same time, on the other hand, should stress that approaches "on own initiative" the evolution by "the compulsion". The enterprise culture is also the human resources management flexible performance; it may form the enterprise huge cohesive force, the affinity and the battle efficiency. The human resources department must through recruit, select, mount guard training to the talented person and so on, will organize cultural the core values to seep to person's brains, causes the talented person to produce to organization's sympathy, will organize the development and talented person's development unifies closely. At the same time, along with organization's development, must unceasingly the rich enterprise culture connotation and the extension, buys in and detains the talented person.

\section{Conclusions}

In brief, the flexible management is one kind of brand-new human resources pattern which based on the information sharing, the hypothesized conformity, the competitive cooperation, the difference supplementary and so on principles establishes. It is not only dynamic; moreover can the forward-looking instruction organization's practice work. Along with knowledge economy's development and technical, the capital global flowing and the proliferation, this kind of pattern will certainly to become the enterprise human resources management the mainstream, also will certainly to have the bigger promoter action to enterprise's development.

\section{References}

[1] Liu Fang. The details of project management and execution of. Technical and Economic and Management Research (2011). (In Chinese)

[2] Yu Jia section. To improve project execution is the key to good project management. Anhui Architecture (2012). (In Chinese)

[3] Wang Jianguo, construction project management in the execution . Construction Management Modernization (2010). (In Chinese)

[4] Xie Aihui. On the competitiveness of our enterprise information. Economist (2014) 
[5] Tan Rucong. Data mining and core competitiveness of enterprises. China's management of information (2015)

[6] Christopher M, Logistics and Supply Chain Management, Strategies for Reducing Cost and Improving Service, Publish House of Electronics Industry, pp. 336-339, 2009.

[7] Cavinato, A total cost value model for supply chain competitiveness, Business Logistics, 2011, pp.256-259. (In Chinese)

[8] Clark, Creating customer value: information-chain based management, Information Strategy, 2007, pp.289-292. (In Chinese)

[9] R.J. Ong, J.T. Dawley and P.G. Clem: submitted to Journal of construction engineering and management (2013)

[10] Information onhttp://www.greensupply.cn/ 